\title{
Formadores da criança e do jovem: interfaces da comunidade escolar
}

\author{
D'Aurea-Tardeli, D. \& Paula, F. V. (Orgs.). (2014). Formadores da Criança e do Jovem: Interfaces da comunidade escolar. \\ São Paulo. Cengage Learning. 154p.
}

Diante das inovações no contexto escolar, com a inserção de mídias interativas, as diferenças nos padrões sociais, a fragmentação do conhecimento e a necessidade de implementação de novas estratégias na busca de promover uma educação de qualidade e que seja sensível às demandas da comunidade escolar, as organizadoras Denise D’Aurea Tardeli e Fraulein Vidigal de Paula, profissionais ligadas à área da Psicologia Educacional e Escolar, abordam o ser humano numa visão holística. Dentro desse foco, para que haja uma formação integral desse "ser", haverá a dependência do entrosamento entre os aspectos físicos, afetivos, cognitivos e sociais.

Esse é o segundo livro da Coleção Escola e Contemporaneidade: temas emergentes à Psicologia da Educação, composta por quatro volumes e traz um questionamento ao professor sobre seu ponto de vista pessoal e ético com relação ao exercício de suas funções e diante de sua profissão. O livro é destinado aos profissionais da área da Educação que estão se preparando para o exercício de suas atividades ou que já exercem a Pedagogia. É composto de cinco capítulos que explicitam as relações estabelecidas entre a escola, os alunos, a família e a comunidade, buscando dialogar e formar estratégias para uma melhor interação entre esses atores sociais.

O primeiro capítulo escrito pelas autoras Marisa Cosenza Rodrigues e Nathalie Nehmy Ribeiro definem a educação como um conjunto de práticas sociais, mostrando a perspectiva da Psicologia Educacional. Ressaltam a complexidade das relações entre desenvolvimento e educação e salientam a relevância do papel do professor numa perspectiva de educação ampliada. Para isso, é necessário que haja, por parte do professor, um conhecimento mais profundo sobre os aspectos do desenvolvimento infantil, propondo uma junção dos conhecimentos da Psicologia Educacional e da Pedagogia, para potencialização da aprendizagem e uso das capacidades do aluno.

Nesse capítulo, as autoras ressaltam a importância da introdução à Literatura Infantil que proporciona benefícios em vários aspectos, como: criatividade, linguagem, cognição, alfabetização, entre outros, numa proposta de leitura mediada, para que haja o aprimoramento e processamento de informações sociais por parte das crianças.

Apresentam uma pesquisa de intervenção envolvendo professoras do ensino fundamental, com um enfoque sociocognitivo na aplicação de uma atividade teórico-prática, com leitura de estórias infantis, com um material lúdico e estimulante. No início do treino, observou-se a descrença das educadoras quanto ao potencial das crianças no processo de aprendizagem. Porém, ao término, pôde-se observar uma grande mudança nesse conceito, com a avaliação positiva das professoras durante o decorrer do processo.

O segundo capítulo escrito por Ricardo Casco, aborda as relações sociais que se desenvolvem no âmbito escolar, tais como: relações de poder entre os professores e o alunado, relações decorrentes das desigualdades socioeconômicas e de poder que se estabelecem entre os alunos, trazendo a escola como um lugar no qual, além da aquisição de saberes das mais variadas áreas do conhecimento, o indivíduo passa por um processo de massificação, homogeneização e despersonalização.

$\mathrm{O}$ autor fala da violência que ocorre frequentemente contra o mais fraco no âmbito escolar, denotando a falência da cultura. Ele também questiona qual o verdadeiro papel da escola que, de acordo com os padrões estabelecidos, deveria ser o de formar pessoas educadas, solidárias e sensíveis, que tivessem possibilidade de refutar os atos de violência cometidos pelos considerados mais fortes e manter um caráter respeitoso. Por fim, o autor traz uma reflexão de que a escola deve trabalhar com condições de ensino objetivas, que propiciem a formação de indivíduos criativos, com autonomia e liberdade, mas, que nas relações sociais, sejam pacíficos, sensíveis e avessos à violência.

Escrito por Luciana Maria Caetano, o terceiro capítulo trata a relação entre a escola e a família e sua influência no processo de aprendizagem. A preocupação dos pais brasileiros quanto à educação de seus filhos, o estabelecimento de limites e valores, ressaltando a contribuição que a escola pode oferecer para a estruturação da relação que se estabelece entre pais e filhos, para que seja um contexto favorável de aprendizagem.

Nesse capítulo, são abordados três preconceitos mútuos que se estabelecem na relação pais, filhos e escola que são: o desafio da promoção de educação na contemporaneidade, a falta de conhecimento e a crise de autoridade. A autora traz uma reflexão sobre a maneira com a qual os educadores se relacionam com as famílias dos alunos e o suporte que a escola deve oferecer para que se alcancem as metas educacionais. 
No capítulo quatro, escrito por Alessandro Soares da Silva e Soraia Ansara, é abordada a necessidade de que o processo educativo não fique limitado apenas ao ambiente escolar, mas que esse relacionamento seja estendido ao entorno dos alunos, incluindo as famílias e a comunidade. Os autores ressaltam a grande dificuldade para se estabelecer esse entendimento, devido à cristalização e a naturalização dos papéis que são ocupados por esses dois sistemas, tornando muito difícil alavancar essa mudança nos padrões sociais.

Os autores abordam a dificuldade na formação do elo família, escola e comunidade, sendo necessária a construção de relações mais democráticas que incentivem os pais a se envolverem mais na educação de seus filhos. Argumentam que o projeto político-pedagógico deve ser uma construção consciente e organizada, que vise uma boa qualidade do ensino e deve ter a participação de todos em sua elaboração. Ao término do capítulo, os autores solicitam que haja uma revisão dos conteúdos e das estratégias em sala de aula, material didático-pedagógico que prepare o aluno a ter autonomia e participação nas atividades, a conscientização do papel dos pais e da comunidade para uma atuação efetiva desses atores sociais no processo de aprendizagem, para que se formem cidadãos que constituam um mundo melhor e mais justo socialmente.

No quinto capítulo, a autora Marilene Proença Rebello de Souza trata da relação entre a Psicologia e a Educação, abordando temas, como a repetência e a evasão escolar, que constituem o fracasso escolar e a função da Psicologia Escolar aliada à Educação para a compreensão desse fenômeno e a busca de estratégias para minimizar seus efeitos. A autora analisa em 25 artigos publicados, quais as tendências da área da Psicologia Escolar e Educacional com relação à formação e a atuação do psicólogo no âmbito escolar brasileiro e suas formas de contribuição. Também, aborda o contexto do cotidiano escolar, ressaltando a necessidade do conhecimento da realidade escolar, mudanças nas formas de ensinar e intervenções centradas na criança, visando o sucesso na aprendizagem. Faz uma reflexão sobre as dificuldades encontradas pelos educadores, sobretudo nas escolas públicas, que prejudicam diretamente o processo de aprendizagem.

Marilene faz uma crítica à medicalização na escola e na sociedade, que reduz os problemas referentes às questões políticas, sociais e educacionais, a problemas de ordem biológica ou orgânica, lançando sobre a criança a culpa por sua não aprendizagem. Esse uso indiscriminado de medicamentos e diagnósticos mal investigados pode dificultar a realização de uma boa intervenção do psicólogo escolar. A autora finaliza o capítulo advertindo sobre a necessidade de que todo aquele que opta pelo ofício na educação, deve ter como objetivo principal o conhecimento da complexidade do cotidiano escolar.

Pode-se considerar que o livro é de extrema relevância na construção de novas ideias para que sejam elaboradas estratégias de ensino que envolvam a escola, os alunos, a família e a comunidade na busca de uma aprendizagem de melhor qualidade, na qual todos os atores sociais possam ter conhecimento das dificuldades desse contexto e se tornarem cidadãos participantes da democracia, visando melhorias na área. Os textos estão escritos com clareza e tendência científica, contando com uma cobertura literária adequada, bem organizada e com exame crítico. As reflexões propostas nos textos e as sugestões apresentadas podem ser de grande auxílio na compreensão do contexto escolar e na busca de soluções para os problemas que envolvem a educação da criança e do jovem.

Recebido em: 22/08/2014 Aprovado em: 08/12/2014

Sobre a autora:

Rilza Xavier Marigliano é graduada em Psicologia pela Universidade São Judas Tadeu e mestranda em Ciências do Envelhecimento pela mesma instituição.

\section{Contato com a autora:}

Av. Dr. José Higino, 516, Mooca, São Paulo-SP

CEP. 03189-040

E-mail: rilzamarigliano@hotmail.com 